\title{
Kierkegaard y la desintegración moderna. Elementos para una crítica inmanente al idealismo en Adorno
}

\section{Kierkegaard and the disintegration of mo- dernity. Elements for an immanent critique of idealism by Adorno}

CHAXIRAXI M. ESCUELA CRUZ

Universidad de La Laguna (España)

\section{RESUMEN}

El propósito de este artículo es investigar la evolución de la lectura que hace Adorno de Kierkegaard para presentarla como un tema central en la formación de su filosofía materialista. Kierkegaard, la construcción de lo estético anticipa en buena medida algunas de las ideas importantes de sus obras posteriores. Y es que si bien critica la ruptura de la dialéctica entre sujeto-objeto que tiene lugar en Kierkegaard, ambos van a coincidir en su ataque al idealismo a través de la crítica inmanente.

\section{PALABRAS CLAVE}

CRÍTICA INMANENTE, DIALÉCTICA, COMUNICACIÓN, MATERIALISMO

\section{ABSTRACT}

The main goal of this article is to investigate the evolution of Adorno's reading of Kierkegaard to present it as a central theme for the formation of his own materialistic philosophy. His work Kierkegaard: Construction of Aesthetic anticipates a good deal of his later work. While he cri- 
ticizes Kierkegaard for breaking off the subject-object dialectic, they converge in their attacks on the concept of idealism through the immanent critique.

KEY WORDS

IMMANENT CRITIQUE, DIALECTIC, COMMUNICATION, MATERIALISM

TRAS REGRESAR DE SUS ESTUDIOS MUSICALES con Schönberg y Berg en Viena, Adorno redacta el trabajo La teoría del inconsciente en la doctrina trascendental del alma ${ }^{1}$ con objeto de habilitarse como Privatdozent en la Universidad de Frankfurt. Bajo la supervisión de Hans Cornelius, pretende asumir elementos de la doctrina psicoanalítica de Freud para tratar de desarrollar una teoría trascendental del conocimiento. A partir del análisis de los momentos de continuidad y de discontinuidad que encuentra entre la filosofía trascendental y las teorías del inconsciente, pretende examinar las posibilidades filosóficas del concepto de «inconsciente» dentro de la teoría del conocimiento. En las nociones de «cosa en sí» y de «espontaneidad» de la Crítica de la razón pura encontrará una apoyatura que le sirva para explicar la formación científica de las filosofías del inconsciente.

Pese a estar bajo la influencia filosófica de su mentor académico, de este texto se desprenden algunos elementos que dan cuenta de los derroteros por los que seguirá su pensamiento. Por un lado, habría que destacar su acercamiento a la filosofía kantiana que jugará un papel central en el desarrollo de su dialéctica negativa. ${ }^{2}$ Por otro, se anuncia el interés que suscitará el psicoanálisis a lo largo

1 Th. W. Adorno, Der Begriff des Unbewußten in der transzendentalen Seelenlehre, en: Gesammelte Schriften, vol. 1. Frankfurt a.M.: Suhrkamp, 1997, pp. 79- 322. Un interesante estudio sobre este trabajo se encuentra en A.Jaitner, Zwischen Metaphysik und Empirie. Zu Verhältnis von Transzenentalphilosophie und Psychoanalyse bei Max Scheler, Theodor W. Adorno und Odo Marquard. Würzburg: Königshausen \& Neumann, 1999. Véase también: A. Arlt, «Zur Möglichkeit einer transzendentalpsychologischen Analyse des Begriffs des Unbewussten in Frühschriften T.W. Adornos», Philosophisches Jahrbuch, 90, (1983), pp. 129-145.

2 Si bien Adorno no elabora ningún estudio monográfico sobre la obra de Kant, como sucediera con otros autores como Hegel o Husserl, son abundantes los momentos de la dialéctica negativa que dan cuenta de la relación con la teoría kantiana, a la que, además, dedica dos cursos: uno centrado en la Crítica de la razón pura (Kants Kritik der reinen Vernunft) en 1959 y otro en la Crítica de la razón práctica (Probleme der Moralphilosophie) en 1963. En ellos alude con asiduidad a los trabajos de Cornelius, en concreto, cuando se refiere a los conceptos de «cosa en sí» $\mathrm{o}$ «causalidad». El contenido de ambas lecciones se encuentra publicado en: Th. W. Adorno, 
de su obra. Si bien en trabajos posteriores matizará esta «lectura de juventud» de Freud pues considerará un grave error el haber obviado el «componente materialista que se designa en él a través del concepto de placer del órgano», ${ }^{3}$ supeditándolo a los aspectos epistemológicos, también subrayará el potencial crítico que encuentra en el psicoanálisis, aunque no en la sublimación de la naturaleza instintiva o en su dimensión terapéutica-ilustrada, sino en su toma de partido por lo reprimido. Cifra su interés en la teoría psicoanalítica en su potencialidad para constituir una verdadera superación científico-materialista de las tesis de la filosofía idealista de la conciencia y en su carácter de «arma contra cualquier metafísica de los instintos». Por eso, en lugar de pretender una oposición entre la filosofía trascendental y las teorías del inconsciente, trata de esclarecer sus momentos de mediación, pues, como apunta, sólo la comprensión de su mutua referencia histórica permite conocer el sentido de su antítesis y de este modo superarla. «La tarea de nuestra crítica inmanente», escribe, «consiste en descubrir las contradicciones o incoherencias existentes en la estructura epistemológica de las doctrinas del inconsciente y, al mismo tiempo, sacar a la luz su contenido oculto trascendental». ${ }^{4}$ Esta tarea de liquidación inmanente de la teoría del conocimiento será un momento fundamental en su filosofía materialista.

Cornelius desaconseja la presentación del trabajo al aducir «falta de originalidad y de contenido innnovador», ${ }^{5}$ y no será hasta 1929 cuando logre habilitarse con un ensayo sobre Kierkegaard, esta vez bajo la supervisión del P. Tillich. ${ }^{6}$

Nachgelassene Schriften. Frankfurt a.M.: Suhrkamp, 2003 y 1996, respectivamente.

$3 C f$. R. Tiedemann, «Editorische Nachbemerkung» en: Th. W. Adorno, Gesammelte Schriften, vol. 1, p. 381. Véase también, H. Brunkhorst, «Adorno, Freud und die Ordung der Freiheit», en: G. Kohler y S. Müller-Doohm, (eds.), Wozu Adorno? Beitrage zur Kritik und zum Fortbestand einer Schlüsseltheorie des 20.Jahrhunderts. Göttingen: Velbrück Wissenschaft, 2008, pp. 51-64.

4 Th. W. Adorno, Der Begriff des Unbewußten in der transzendentalen Seelenlehre, op. cit., p. 113.

5 S. Müller-Doohm, Im Niemandsland. Eine intellektuelle Biographie von T. W. Adorno. Frankfurt a.M.: Suhrkamp, p. 155.

6 Th. W. Adorno, Kierkegaard. Konstruktion des Ästhetischen, en: Gesammelte Schriften, vol.2,1997,pp. 7-265. Pese a que el interés bibliográfico por esta obra ha sido escaso, es posible señalar algunos monográficos que le han prestado atención como momento central para el desenvolvimiento de su pensamiento hasta Dialéctica negativa, entre ellos: H. Deuser, Dialektische Theologie: Studien zu Adornos Metaphysik und zum Spätwerk Kierkegaards. München: Kaiser, 1980, V. Gómez, El pensamiento estético de Theodor W. Adorno. Valencia: Cátedra, 1998, y J.A. Zamora, «El joven Th. W. Adorno y la crítica inmanente del idealismo», Azafea, revista de filosofía, 11, (2009), pp. 45-72. Por su parte, Tillich escribe una reseña sobre la aparición de la obra de Adorno: Cf. Kierkegaard: Konstruktion des Aesthetischen, Reviewed by P. Tillich, The Journal of Philosophy, vol. XXXI, n 23, (1934), p. 640. 
Aquí se expresa lo que podría considerarse un cambio orientación en la obra de Adorno a partir de los años treinta con respecto a las posiciones del psicologismo trascendental que impregnaban sus primeros ensayos. De forma explícita comienza a ser evidente en estos textos académicos una forma de articulación distinta de los problemas filosóficos que, sin embargo, ya estaba presente en el ámbito extraacadémico y personal del joven Adorno. Pues, mientras sus trabajos de promoción en la Universidad presentaban algunos rasgos del idealismo de su tutor, durante estos años también se encuentra determinado por otras influencias que habrían de incidir en su proceso de formación filosófica. La lectura de obras como El espíritu de la utopía de Bloch o Historia y consciencia de clase de Lukács le proporciona las bases para un acercamiento a Marx y Hegel distinto al marxismo ortodoxo y que, con matizaciones, influirá en el desenvolvimiento de su interpretación negativa y materialista de la dialéctica. Sin embargo, será su relación con Horkheimer y, sobre todo, con Benjamin, lo que será considerado de interés en la nueva dirección de su pensamiento, como reconoce en una carta a Alban Berg. ${ }^{7}$ Este cambio de perspectiva filosófica, si bien se acentuará en los años treinta, tiene su origen en el fondo de la argumentación de sus primeros escritos sobre Husserl y Kierkegaard. ${ }^{8}$

En su discusión con estos autores se expresa el empeño por hacer frente a un panorama filosófico marcado por una situación de crisis histórica y social, una vez que ha fracaso el proyecto moderno de racionalidad. Tras el derrumbe del idealismo hegeliano, pero también de los proyectos socialistas emancipadores que se planteaban como alternativas al mundo burgués, cree que el punto de partida de la reflexión filosófica ha de ser el abandono de las pretensiones de totalidad y sentido, que eran los rasgos idealistas que desde el principio acompañaban a la filosofía. La discusión con el idealismo, no como periodo histórico concreto, sino como el impulso inherente a todo pensamiento

7 Th. W. Adorno y A. Berg, Briefwechsel 1925-1935. Frankfurt a.M.: Suhrkamp, 1997, p. 75. Tiedemman y el resto de editores de la obra completa coinciden en resaltar esta transición cuando señalan: «si se quiere llamar por nombres, depende muy estrechamente de la separación de Cornelius y la unión a Walter Benjamin» (Cf. Tiedemann, op. cit., p. 383).

8 El propio Benjamin supo ver el valor de la tesis de Adorno, más allá de su contribución al renovado interés bibliográfico sobre el filósofo danés, al considerar incluso la posibilidad de que todos los libros posteriores del autor pudieran derivar de éste. En una reseña a la revista Vorsichte Zeitung escribe: «el último intento de retomar o prolongar enérgicamente el pensamiento de Kierkegaard procedió de la teología dialéctica de Karl Barth. Las olas de esta corriente teológica acaban confluyendo con los círculos creados alrededor del pensamiento existencial de Heidegger. El presente ensayo [...] aborda el mismo tema desde una perspectiva completamente distinta. Su autor no hace avanzar a Kierkegaard sino, al contrario, lo hace retroceder hacia el interior del idealismo filosófico, a cuyo hechizo sucumbió impotente la propia intención teológica del pensador» (Cf. W. Benjamin, Kierkegaard. Das Ende des philosophischen Idealismus, en: Gesammelte Schriften, vol. 3. Frankfurt a.M., Suhrkamp, p. 38). 
guiado por el interés de reconciliar razón y verdad, será una constante en la filosofía adorniana y también el lugar en el que justifica la forma negativa de su dialéctica materialista. Considera que defender la posibilidad de la filosofía requiere no sólo abandonar un ideal de pensamiento comprendido como teoría justificadora de la racionalidad de lo real, sino también replantear la pregunta acerca de formas que orientan el obrar filosófico. Para Adorno esta pregunta pasa necesariamente por poner de manifiesto una «liquidación inmanente del idealismo», por superar sus aporías y contradicciones. Pero no desde una nueva teoría alternativa, sino acudiendo al interior de sus propias categorías para revelar en ellas el momento en el que se tornan falsas, y así lograr revocarlas. Esto significa cuestionar los contenidos gnoseológicos de la tradición filosófica para ponerlos al descubierto como categorías de dominio. Esta forma de comprender la liquidación inmanente al idealismo, que posteriormente llamará el «asalto a la tradición dialéctica» y que será el fundamento de su Dialéctica negativa, queda expresada ya en estos primeros textos. En ellos expondrá a Kierkegaard y Husserl como representantes de un ejercicio de revocación del sistema idealista con sus propios medios.

La correspondencia de finales de los años veinte con Berg y Kracauer permite observar el temprano interés que en Adorno había despertado la filosofía antiacademicista y existencial de Kierkegaard. ${ }^{9}$ Frente al idealismo y, sobre todo, frente la filosofía de la historia hegeliana, representaba un modo distinto de comprender el concepto de filosofía en el que persiste un momento de convergencia entre teoría del conocimiento y estética. Sin embargo, la tesis que pretende defender en su Habilitationschrift es que, pese al empeño por situarse frente a la filosofía de Hegel, en el pensamiento de Kierkegaard persiste un componente fundamentalmente idealista, que aparece en su teoría de lo estético y en su comprensión de la subjetividad como «interioridad sin objeto». Si bien comparte con él su rechazo de la ontología idealista, también subraya el peligro que conlleva la absolutización de la existencia subjetiva, tal como el pensador danés la expresa en la construcción de su estética. ${ }^{10}$

9 ABerg, por ejemplo, le expresaba su «empecinamiento en el problema de la personalidad e interioridad de lo individual» (Th. W. Adorno y A. Berg, op. cit,. p. 88).

10 La temprana concepción de la relación entre filosofía y arte será, sin duda, determinante para el desarrollo de su propio pensamiento. Ya en este texto pone de manifiesto la necesidad de comprenderla, no como la disolución de la teoría en el ámbito de lo estético, sino como una relación de convergencia en la que situar las bases para una crítica a la praxis dominante y deformadora. A esto apuntan las primeras líneas del texto: «la ley formal de la filosofía exige la interpretación de lo real en la relación acorde de los conceptos. Ni la manifestación de la subjetividad del pensador, ni la unidad y coherencia de la obra en sí misma deciden sobre su 
El trabajo comienza distinguiendo tres acepciones de lo estético que aparecen en la obra de Kierkegaard, articuladas en torno a su interés por desarrollar una teoría del arte material distinta al clasicismo. ${ }^{11}$ En relación al uso del lenguaje cotidiano, el concepto de «estética» designa, en primer lugar, el ámbito de estudio del arte y de las obras artísticas. Más importante aún es la utilización de un segundo significado de lo estético como un tipo de actitud o «esfera», distinta e inferior a la ética y a la religiosa, que se caracteriza por la inmediatez y la exterioridad. Finalmente, y aquí se centrará la atención de su trabajo, alude a la utilización de la estética como forma de comunicación en la que se expresa la interioridad del sujeto en su relación con el objeto conocido. En su rastreo de la función que ejerce lo estético, Adorno descubre un contenido filosófico concreto que excede el nivel de la teoría del arte. Por eso, pretende poner de manifiesto la comprensión del momento de lo estético, no como un elemento referido con exclusividad al ámbito de lo artístico, sino como categoría de conocimiento. Trata de «interpretar la obra de Kierkegaard como un todo; en ella la estética no significa simplemente teoría de arte sino que, en términos hegelianos, implica referirse a la posición del pensamiento ante la objetividad». ${ }^{12}$ Por tanto, el contenido filosófico que encuentra será la construcción de una teoría del sujeto. Pues ve en Kierkegaard la presencia de un concepto de subjetividad que, pese a ser formulado en un comienzo como contrario a la filosofía hegeliana y fichteana, termina por revelarse como idealista.

Al aludir a la «posición del pensamiento ante la objetividad», como cuestión presente en la construcción kierkegaardiana de lo estético, Adorno adelanta uno de los ejes fundamentales que vertebrarán la orientación materialista de su pensamiento y, en concreto, su posición crítica respecto al idealismo y la modernidad filosófica. Se trata de la necesidad de plantear una forma de comprender la relación entre sujeto y objeto distinta a la presentada por el idealismo y por la epistemología moderna. A lo largo de su obra va a considerar como una de las tareas principales de la filosofía la revisión de la relación entre el sujeto y el objeto del conocimiento, una revisión que los comprenda como «nudos históricos»

carácter como filosofía. Sólo esto: si lo real entra en los conceptos, se acredita en ellos y los fundamenta razonablemente [...] Si la filosofía, como pensar subjetivo, ha abandonado completamente la totalidad, lo nuevo que aparece le hace oír la dudosa llamada de lo poético, siendo los conceptos dialécticos su verdadero instrumento» (Th. W. Adorno, Kierkegaard. Konstruktion des Ästhetischen, op. cit., pp. 9 ss.).

11 Un año después de habilitarse, Adorno imparte, por recomendación de Tillich, su primer seminario en la universidad. En ella, de nuevo, el hilo conductor será Kierkegaard y su concepción de la estética. Los protocolos de estas lecciones se encuentran publicados en: «Aufzeichnungen zur Ästhetik-Vorlesung von 1931/32», Frankfurter Adorno Blätter, I. München: text+kritik, 1992, pp. 35 ss.

12 Th. W. Adorno, Kierkegaard. Konstruktion des Ästhetischen, op. cit. p. 262 
frente a la exigencia de totalidad e identificación inherente al pensamiento. ${ }^{13}$ Esta tarea, que atraviesa su teoría materialista del conocimiento y de la experiencia se encuentra planteada ya en su Habilitationschrift. Kierkegaard articula una teoría estética material sobre la primacía de lo subjetivo, con la que pretende distanciarse del formalismo estético y, en última instancia, superar el idealismo hegeliano. Para ello, rechaza aceptar en el ámbito de lo estético todo aquello que no provenga de la inmediatez de la subjetividad, de su interioridad. Este deseo de distanciarse del formalismo estético y, en concreto, de la tradicional oposición entre forma y contenido, es comprendido por Adorno como una tarea infructuosa: «al no tener en cuenta en su análisis la producción recíproca tanto de las formas como de los contenidos, se impone necesariamente a la teoría el primado del principio formal». ${ }^{14}$

En Kierkegaard el arte se entiende como forma de «comunicación», no de lo objetivo, sino del sujeto mismo que imprime la forma al objeto. Éste es privado de sus contenidos y, por consiguiente, desaparece su valor interno a favor de lo que determina la subjetividad. Por eso, la existencia del objeto estético es sólo el resultado de la inmediatez del sujeto. De ahí que para él «la grandeza atribuible al objeto es lo que el sujeto trascendental le imprime como idea y totalidad». ${ }^{15}$ Por eso cree que Kierkegaard no logra superar las tesis idealistas de las que se había esforzado en separarse: «El cómo tiene su derecho filosófico - descubierto por Kierkegaard frente al plano dualista de forma y contenido-como expresión de una legalidad objetiva en el aparecer de la verdad. Pero, al mismo tiempo, su doctrina debilita este derecho al dejarlo a merced de la subjetividad, que con la reduplicación añade a las cosas la verdad como algo nuevo, al separar la verdad y las cosas en las que aparece y al atribuir existencia a la verdad y contingencia a las cosas». ${ }^{16}$

A pesar de que la obra del pensador existencialista se encontraba impulsada por el deseo de superar el sistema hegeliano con sus propios medios no lo logra, pues termina por repetir idénticos puntos de partida idealistas. Por eso, «el filósofo de la interioridad» proporciona a Adorno algunas de las bases para determinar el componente inmanente que le dará a su crítica al sistema idealista y a su posición ante la contemporaneidad filosófica. Las objeciones que opone al idealismo no son expuestas a partir de un tercero externo. Por el contrario, el ejercicio de crítica materialista e inmanente partirá, en adelante,

13 «La filosofía consiste principalmente en determinar la relación entre sujeto y objeto durante el proceso del conocimiento» (Cf. Th. W. Adorno. Der Begriff der Philosophie. Vorlesung Wintersemestrer 1951/52, en: Frankfurter Adorno-Blätter, II. op. cit., p. 24). Este tema será desarrollado posteriormente en el pequeño artículo que lleva por título «Sobre sujeto-objeto».

14 Th. W. Adorno, Kierkegaard. Konstruktion des Ästhetischen, op. cit., p. 28.

15 Ibid., p. 32.

16 Ibid., pp. 191-192. 
de la búsqueda de estas objeciones en el interior mismo del sistema idealista. Es decir, de su estructura lógica y de sus propias categorías gnoseológicas con el fin de identificar en ellas las contradicciones que conducen a su revocación. Se trata, como expresará en Dialéctica negativa, de «tocarle su misma melodía» con el objetivo de consumar su liquidación.

Esto supone buscar las causas del fracaso del proyecto idealista en el interior de sus componentes, fundamentalmente, en su modelo de subjetividad y objetividad. Algo que ve de forma ejemplar, aún sin pretenderlo, en la filosofía de Kierkegaard. Éste presenta la defensa de una subjetividad abstracta que se refugia en su interioridad y que aparece vacía de determinaciones externas. Con ello trata de esbozar una respuesta no sólo frente a la teoría hegeliana del espíritu absoluto, sino también frente a la descomposición y la cosificación social que amenazaba realmente al individuo. Sin embargo, en esta figura del intérieur, de la «interioridad sin objeto», Adorno verá una continuación de la filosofía idealista del sujeto que posteriormente llamará el «mito de la subjetividad constitutiva» y que aparece aquí como un ejemplo temprano de lo que significa su crítica materialista al idealismo. Y es que, para él, este refugio en la interioridad, lejos de representar una defensa del sujeto o una liberación de las formas de dominio a las que se encuentra sometido, supone en realidad la inversión definitiva de su función crítica y la desaparición del verdadero potencial de resistencia ante lo objetivo amenazante. Por eso, cuando el Yo kierkegaardiano encuentra la salida a la presión de la objetividad en el encierro en su individualidad, acaba por repetir, sin quererlo, el modelo idealista de la subjetividad constitutiva. ${ }^{17}$

La fuerza que impulsa a los sistemas idealistas a sostener la imagen de un sujeto autodeterminado que se sobrepone a la coacción externa, remitiéndose a su interior, supone para Adorno una fuerza mal dirigida, pues «el pensamiento no advierte en absoluto que lo que buscaba se encontraba en la búsqueda misma y que, si no buscaba en ésta, no encontraría lo buscado ni en toda la eternidad. A la filosofía le sucedía lo que a un hombre que busca sus gafas y las lleva puestas: busca entre lo que tiene delante de sus narices, pero nunca busca en sus narices y por eso nunca las encuentra».18

17 Con motivo de la publicación de una obra del que fuera su alumno H. Schweppenhäuser, Adorno vuelve a señalar la misma tesis que había sostenido en su trabajo: «pese a su antipatía hacia Hegel, Kierkegaard no ha logrado examinar por completo el problema del idealismo. De forma naiv, se conservan en el enemigo del idealismo incontables categorías del ámbito idealista, algunas de Hegel y sobre todo de Fichte. Por eso, mientras que su ataque se dirige a su objeto, al mismo tiempo no logra anular el sistema con la suficiente fuerza» (Th. W. Adorno, Fällige Revision, en: Gesammelte Schriften, vol. 20.1, op. cit., p. 260). El libro de H. Schweppenhäuser se encuentra publicado con el título Kierkegaards Angriff auf die Spekulation. Eine Verteidigung. Frankfurt a.M.: Suhrkamp, 1967.

18 Th. W. Adorno, Kierkegaard. Konstruktion des Ästhetischen, op. cit., p. 42. 
Creer que al eliminar en el sujeto la mediación objetiva se logra superar la parálisis y cosificación supone, a su juicio, un error, puesto que genera un tipo de parálisis aún más acuciante, basada en la imagen de una subjetividad reducida a mera tautología, a la que le han sido sustraídos sus componentes materiales y objetivos y, con ello, también su capacidad de resistencia. Por eso, la filosofía idealista basada en la imagen del sujeto constituido en sí mismo y liberado de sus determinaciones naturales, pero también formador de la objetividad a la que determina, revela desde su origen un carácter antinómico. Cuanto mayor es su intento por alejarse del objeto y mayores sus deseos de indeterminación e inmediatez, tanto más termina por ser reducido a lo cósico y tanto menos deja de ser un sujeto real. Esta antinomia -que va a considerar «irresoluble en el marco de la gran filosofía»- dinamita los presupuestos de la filosofía del sujeto. Pues si su punto de partida es la identidad y la reducción al yo inmediato libre de determinaciones materiales, esta inmediatez termina por mostrarse contraria a sí misma. Poner de relieve esta antinomia será uno de los objetivos fundamentales a los que, desde el principio, hace frente la filosofía materialista de Adorno, y también un aspecto específico de su comprensión negativa de la dialéctica.

\section{III}

Adorno sostiene que en el concepto de «interioridad» de Kierkegaard se reproduce la misma antinomia idealista, pues presenta un idéntico concepto de subjetividad que se basa en la relación consigo mismo y con sus determinaciones intelectuales y que se cierra ante lo otro distinto al pensamiento. Por eso, afirma que «lo que rechazaba en Hegel como actitud de espectador, lo que en él se llama enajenación y objetividad objetual, se repite ahora en las determinaciones fundamentales del sujeto». ${ }^{19}$ Esto no significa, sin embargo, que interprete la filosofía de Kierkegaard como una recuperación sin matices de la dialéctica hegeliana, pues aclara que ni es un filósofo de la identidad, ni reconoce un ser positivo que trasciende a la conciencia. Por eso, coincide con él en su negación de la ontología idealista que identifica razón y verdad: «el Yo-Yo de Fichte y el sujeto-objeto de Hegel son para Kierkegaard objetivaciones bajo el signo de

19 Ibid., p. 245. Treinta años después recupera esta tesis en sus lecciones sobre ontología y dialéctica, para señalar su interés en «mostrar cómo en esta filosofía anti-ontológica se esconde en realidad una ontología implícita» (Cf. Th. W. Adorno, Ontologie und Dialektik (1960-61), en: Nachgelassene Schriften vol.7. Frankfurt a.M.: Suhrkamp, 2002,p. 178). También aquí pretende tomar distancia de la interpretación heideggeriana del existencialismo de Kierkegaard. Por ello, defiende una comprensión de la noción de «existencia como la relación del hombre consigo mismo, como una forma de reflexión, sólo que con la diferencia de que en Kierkegaard, con respecto a Hegel, los conceptos como existencia o ser [...] son adoptados de forma hipotética, mientras que en Heidegger la representación de la separación entre el Dasein como lo existente y el Ser es concebido como una forma de proto-relación» (Ibid., p. 133). 
la identidad. Y son negadas, precisamente, en la medida en que representan el puro ser de la existencia frente al individuo singular existente». ${ }^{20}$ Sin embargo, el error que le atribuye es el de haber eliminado el momento hegeliano de la mediación, interpretándolo como un término medio, para hablar, en su lugar, de una subjetividad aislada y absolutizada. ${ }^{21}$ Como consecuencia de esto, y pese a pretender desarrollar un método dialéctico, éste termina siendo falseado pues deja de lado el momento de mediación. No logra superar el sistema de la identidad, sino que en él «Hegel está vuelto hacia dentro [...], y si es cierto que la concibe dentro del esquema de la interioridad, es la verdadera historia la que le hace entrar en ese esquema».22

Por eso, el intérieur de Kierkegaard será tan poco verdadero como el todo hegeliano, pues la conciencia comprendida a partir de la figura de la interioridad niega los elementos materiales externos a ella para afirmarse como un en-sí. En otras palabras, ha de mostrarse como un en sí para negar el en-sí. En el esfuerzo por articular y dominar los elementos externos la propia subjetividad termina disolviéndose en algo universal. Adorno ve en esta negación el momento de sacrificio y de renuncia del espíritu, algo que interpreta, en última instancia, como momento de la disolución inmanente del sistema idealista: «como el espíritu del individuo no es en él solamente el arquetipo de todo espíritu sino la naturaleza misma, la cual no aparece más que en el espíritu, el sacrificio -última categoría de la naturaleza a la que él se eleva y al mismo tiempo categoría de la destrucción de lo natural- es también en él sacrificio del espíritu». ${ }^{23}$

El instante de la liquidación interna de la lógica idealista es articulado, entonces, a partir de los conceptos de «dominio»y «sacrificio». Es importante señalar que se trata de conceptos que continuarán ejerciendo un papel fundamental en su revisión de la filosofía moderna y en la formulación de su teoría social. Algo que muestra, como se ha venido insistiendo, la necesidad de leer estos primeros trabajos académicos como lugares en los que se encuentran coagulados gran parte de los momentos sobre los que se va construyendo la filosofía materialista adorniana. La identidad que pretende en su absolutización no equivale únicamente a la aniquilación del objeto, sino también a la del sujeto mismo, al empobrecimiento tanto de la experiencia sensible como del propio pensamiento. Todo intento por salir del contexto natural para afirmar el sí-mismo sobre la base del distanciamiento y la opresión de la naturaleza externa, acaba

20 Th. W. Adorno, Kierkegaard. Konstruktion des Ästhetischen, op. cit., p. 102.

21 Th. W. Adorno, Aspekte, Drei Studien zu Hegel, en: Gesammelte Schriften, vol. 5. Frankfurt a.M.: Suhrkamp, 1997,p. 258. Idéntica acusación sostendrá en sus lecciones de 1965, publicadas con el título Metaphysik. Begriff und Probleme, en: Nachgelassene Schriften, vol. 14. Frankfurt a.M.: Suhrkamp, 1998, pp. 190-191.

22 Th. W. Adorno, Kierkegaard. Konstruktion des Ästhetischen, op. cit., p. 49.

23 Ibid., p. 152. 
por relevarse como una empresa frustrada al compartir idéntico mecanismo de violencia orientado al dominio. La tesis según la cual la absolutización del espíritu sobre la naturaleza del sistema idealista -y repetida aquí por el filósofo danés- se realiza en virtud de la caída en la misma naturaleza, será una constante en la obra de Adorno y constituirá uno de los núcleos de Dialéctica de la Ilustración. ${ }^{24}$ Una idea que aparece esbozada en su Kierkegaard: «el poder sobre la vida natural es, así, un poder sólo para destruirla en el espíritu, y no de reconciliación. Pero la destrucción de la vida natural [...] es correctamente entendida como una destrucción fantasmal, pues aquí no sólo es la vida natural destruida que está cautiva de mitología. Por eso, no conoce la esperanza y, en la doctrina kierkegaardiana de la fe, la paradoja deforma la esperanza en la pura destrucción de la naturaleza por el espíritu». ${ }^{25}$

Sin embargo, y aquí reside un aspecto fundamental que hay que destacar en este escrito, Adorno quiere mostrar un momento de verdad en esta concepción de la subjetividad y, por extensión, en la misma noción idealista de sujeto, pues «al establecer la conciencia de la existencia condicionada (que no puede ser deducida de manera suficiente a partir de sí misma, como suprema contradicción de su idealismo), Kierkegaard se convierte en un crítico del sistema». ${ }^{26}$ El espíritu se convierte en mítico cuando olvida la dimensión material que lo determina en favor de una vuelta a la interioridad. Sin embargo, por otro lado, lo mítico también representa para él una forma de protesta de lo múltiple en la naturaleza frente a la unidad lógica que se identifica con el principio dominador del espíritu. En esta duplicidad del significado de lo mítico, que tan importante será en su filosofía dialéctica, encuentra el momento crítico que representa la filosofía de Kierkegaard frente al idealismo hegeliano, pues «pese a detestar la mediación, acentuaba más que Hegel una mediación central que éste conocía: la del yo por el no-yo, la del sujeto constituyente por aquello que según el esquema idealista sólo puede haber sido constituido por el sujeto».27

Aún sin nombrarla, Adorno alude aquí a una figura que, en adelante, representará un papel determinante en su construcción materialista de la filosofía: la «prioridad del objeto». El sujeto absoluto de Kierkegaard y su expresión idealista presentan, al mismo tiempo, un doble componente de falsedad y de verdad. Se manifiesta como falsa consciencia cuando olvida su dimensión material y objetiva y se le atribuyen unas características que, en realidad, han sido sustraídas de lo objetivo social. Pero, precisamente en virtud de esta sustracción, en el sujeto

24 Es interesante señalar de qué forma algunos de los conceptos más importantes de Dialéctica de la Ilustración, como «sacrificio», «mito» o «dominio de la naturaleza», se encuentran ya articulados por el joven Adorno en su obra sobre Kierkegaard.

25 Ibid., p. 155.

26 Ibid., p. 152.

27 Ibid., p. 251. 
idealista reside un momento de verdad, pues da cuenta de la influencia real que ejercen los procesos sociales y materiales sobre los individuos en la sociedad del intercambio. Es decir, el peso de lo objetivo sobre el sujeto. Por tanto, al confirmar la prioridad del objeto el sujeto idealista se torna verdadero. Y esto, sostiene, se encuentra ya en el existencialismo kierkegaardiano, al ser «una metafísica del sujeto absoluto contraída al individuo de forma nominalista y, al mismo tiempo, un ataque frente a la ideología del sistema de beneficios». ${ }^{28}$

Sólo si se constata el engaño que supone mantener el mito del sujeto como autónomo e indeterminado o, en otras palabras, sólo si se logra invertir la imagen idealista de la subjetividad sobre sí misma y se revelan las contradicciones que se generan en sus planteamientos, será posible alcanzar su transformación. Por eso, este componente de verdad que Adorno encuentra en la figura kierkegaardiana de la interioridad puede ser considerado como expresión temprana de una crítica materialista e inmanente a la filosofía de la identidad, pues abre paso a eso distinto (lo - no idéntico) que, desde dentro, logra dinamitar las pretensiones de un sujeto puro comprendido como espíritu. Estos elementos específicos de su materialismo, que vertebran su trabajo sobre Kierkegaard, se dirigen hacia una revocación de las relaciones de dominio que se ciernen sobre los individuos y que impiden su completa emancipación. Alcanzar este sujeto libre y emancipado, que había prometido el sistema idealista, se convertirá, en adelante, en el objetivo utópico de su filosofía materialista.

\section{IV}

La tesis de habilitación del joven Adorno se presenta como un texto central para comprender la interpretación dialéctica y materialista de su teoría del sujeto a la luz de las consecuencias que generan las formas imperantes de la sociedad moderna. Algo de lo que es consciente cuando escribe: «lo que Kierkegaard llama la desintegración (Zerfall) de las relaciones fundamentales de la existencia humana es, en el lenguaje filosófico de su época, la alienación del sujeto y del objeto. De esta alienación ha de partir la interpretación crítica de Kierkegaard. No es que esta interpretación piense la estructura de la existencia, dentro de un «proyecto ontológico», como una estructura de sujeto y objeto. Las categorías de sujeto y objeto tienen un «origen histórico [...]. Y constituyen, al mismo tiempo, el supuesto concreto del discurso kierkegaardiano sobre la existencia humana. Éste oculta una antinomia del pensamiento de Kierkegaard que se hace patente en la relación sujeto-objeto, a la cual se puede reducir la desintegración». ${ }^{29}$

Encuentra en sus categorías epistemológicas, que expresan la incapacidad del sujeto para alcanzar de forma inmediata su correlato objetivo, un reflejo fiel

28 Ibid., p. 252.

29 Ibid., pp. 41-42. 
del «hechizo» que se extiende sobre individuos y cosas bajo las condiciones sociales existentes. En otras palabras, refleja la destrucción de las posibilidades auténticas de emancipación y de libertad en una realidad social que se presenta como totalidad antagónica regida por el principio de igualdad e intercambio. Por eso, como después hará Marx, «Kierkegaard reconoció en sus inicios la miseria de la situación creada por el gran capitalismo en sus inicios». ${ }^{30}$ Es necesario insistir en esta idea como clave para comprender la alianza entre crítica al conocimiento y crítica social que tiene lugar en el seno de su pensamiento y que supone una aspecto determinante en su filosofía materialista. Una alianza que, si bien se hace explícita en su obra madura, ya aparece en el texto de Kierkegaard cuando detecta como fundamento real en lo existente «el conocimiento de la cosificación de la vida social, de la alienación del hombre por una realidad que sólo se le presenta como mercancía». ${ }^{31}$ Aquí se muestran algunas de las consideraciones que elaborará más adelante en torno a la figura del sujeto trascendental y a la idea de libertad lograda a partir del desprendimiento progresivo de lo objetivo. Pero el fortalecimiento del sujeto en la filosofía idealista termina por convertirse en debilidad y empobrecimiento del individuo real que se encuentra sometido a la alienación de las estructuras sociales. En uno de los anexos del libro titulado «La doctrina kierkegaardiana del amor» apunta a la misma línea de pensamiento cuando afirma que: «Kierkegaard señaló una tendencia actual de la sociedad de masas que en su época hubo de ser muy latente: la sustitución del pensamiento espontáneo por la adaptación automática, tal como se opera en relación con las formas modernas de información. Por conservador que se muestre en su hostilidad a las masas, en tal hostilidad se esconde, igual que en Nietzsche, cierta percepción de la mutilación del hombre por los mecanismos de dominación que lo convierten en masa».32

La expresión de la interioridad representa la resistencia del sujeto a convertirse en un ser-para-otro $y$, al mismo tiempo, la exigencia de autenticidad en la sociedad de intercambio como forma de identidad consigo mismo. Pero, precisamente esta exigencia lo condena a su eliminación. Esto muestra para Adorno el carácter antinómico de la filosofía idealista del sujeto: aunque su

30 Ibid., p. 59.

31 Ibid., p. 58.

32 Ibid., p. 229. En Teoría estética volverá a desarrollar esta idea, cuando señala la interioridad como resultado del proceso de trabajo: «tenía que cultivar un tipo antropológico que por deber, casi voluntariamente, lleve a cabo el trabajo asalariado que el nuevo modo de producción necesita y al que lo obligan las nuevas relaciones sociales de producción. Con la creciente impotencia del sujeto que es para sí, la interioridad se ha convertido en ideología, en el espejismo de un reino interior cuyos habitantes se resarcen de lo que se les niega socialmente» (Th. W. Adorno, Ästhetische Theorie, en: Gesammelte Schriften, vol. 7. Frankfurt a.M.: Suhrkamp, 1997, p. 176). 
objetivo era alcanzar la autoconservación de un individuo liberado del peso de lo objetivo, sucede lo contrario en virtud de esta misma pretensión. «Frente a la cosificación y la socialización de todas las relaciones entre los hombres en los cien años siguientes a la muerte de Kierkegaard, la posición del individuo, al que se le concedía la más alta dignidad, se manifestaba como refugio frente a la explotación dominante que, enemiga de la determinación individual, degrada a cada uno a su papel. Kierkegaard pudo hacerse popular porque el individuo absoluto, que él oponía en su época a las masas del gran capitalismo que entonces comenzaban a hacerse visibles, ha acabado presentándose ante esas como la situación de todos».33

Esta idea constituye la más importante objeción al idealismo que va a ejercer su filosofía materialista: mostrar la imposibilidad de su realización como consecuencia, no de una crítica externa, sino de sus propios presupuestos. Aquí aparece la afinidad que encuentra entre el momento teológico de Kierkegaard y la izquierda hegeliana: la negación al espíritu idealista de la capacidad para determinar lo absoluto. «El hecho de que la subjetividad sea el lugar de la verdad significa que la razón no puede ser la dueña de lo absoluto, sino que la verdad se esconde en una forma de relación de la subjetividad que no puede ser situada más allá de la medida objetiva». ${ }^{34}$ Por eso, lo que está en la base de esta idea y, en general de todo el escrito, es el esfuerzo por lograr una superación del idealismo utilizando como instrumento sus propias categorías. En mi opinión, un elemento importante en su comprensión materialista de la filosofía y determina, como le expresa a Horkheimer, su deseo de desarrollar una liquidación inmanente de la filosofía idealista. ${ }^{35}$

Adorno ejercerá esa tarea interrogando a los contenidos gnoseológicos de la tradición filosófica, para que las propias formas de fundamentación epistemológicas se desvelen como categorías de dominio y, al mismo tiempo, como instrumentos de liberación. Por eso, la dialéctica materialista adorniana en tanto crítica al idealismo adoptará la forma de una «metacrítica de la teoría del conocimiento» que reflexiona sobre sí misma y también sobre sus componentes. ${ }^{36}$

33 Th. W. Adorno, Kierkegaard. Konstruktion des Ästhetischen, op. cit., p. 244.

34 Th. W. Adorno, Ontologie und Dialektik.1960-61, op. cit., p. 181.

35 Th. W. Adorno y M. Horkheimer, Briefwechsel 1927-1937, vol. 1. Frankfurt a.M.: Suhrkamp, 2003, p. 600.

36 En una de sus lecciones impartidas durante el semestre de invierno de 1957-58 Adorno realiza una distinción entre tres posibles significados del concepto de inmanencia: «inmanencia lógica», comprendida como la concordancia de las categorías y los supuestos entre sí; «inmanencia de la conciencia», referida a los actos de la conciencia y, en último lugar, «inmanencia metafísica» que, opuesto a «trascendencia», haría referencia a todo lo aprehendido bajo los límites de la experiencia posible ( $C f$. Th. W. Adorno, Vorlesung zur Einleitung in die Erkenntnistheorie. Frankfurt a.M.: Junius-Drucke, 1973, pp. 132 ss.). Posteriormente, en Terminología filosófica 
Interpretar, pues, las categorías del pensamiento como fuentes de dominio supone poner de manifiesto la necesidad de encontrar en ellas mismas el momento de su revocación. Por eso, el empeño de la metacrítica materialista de enfrentar conceptos contra conceptos se asemeja a la del barón de Münchhausen. Pues si el personaje de Raspe pretendía salir del pozo en el que había caído tirándose de sus propias coletas, también el esfuerzo de la teoría será curar las heridas que ella misma se ha infringido. Ésta es la tarea que Adorno asigna al pensamiento materialista como resultado de su análisis crítico de la actualidad de la filosofía: la interpretación dialéctica de la realidad y su deseo de transformación. Una tarea que, como se ha visto, fundamenta durante los años de juventud en su confrontación con Kierkegaard, pero que se concretará a comienzos de los años treinta bajo la decisiva influencia de Benjamin y Horkheimer en dos textos fundamentales: «La actualidad de la filosofía» $\mathrm{y}$ «La idea de historia natural». En esos trabajos, que desarrolla en su primera etapa como Privatdozent en la Universidad de Frankfurt, se aprecia una clara continuidad con los problemas que habían sido apuntados en sus primeros textos. En concreto, su interés por formular una filosofía materialista comprendida como interpretación crítica e inmanente del conocimiento y de lo social. Una idea que, a pesar de sus continuas modulaciones, seguirá manteniendo a lo largo de su obra y que determinará el desarrollo de su dialéctica negativa y sus contribuciones a los problemas epistemológicos y estéticos.

Chaxiraxi M ${ }^{a}$ Escuela Cruz es Doctora en Filosofía por la Universidad de La Laguna (2011). En la actualidad es beneficiaria de una beca postdoctoral en el Husserl Archiv de la Albert Ludwigs Universität (Freiburg i.B.) concedida por el DAAD.

Líneas de investigación:

Teoría Crítica y Hermenéutica

Publicaciones recientes:

(2010) «Metamorfosis de lo histórico paralizado en naturaleza. Th. W. Adorno y la idea de una historia natural», en: AA.VV., Limites y fronteras, Universidad de La Laguna, pp. 240245 .

volverá sobre estos términos, prestando esta vez especial atención al significado de crítica inmanente: «Ante todo es importante la diferencia entre una crítica inmanente que mide un objeto por sus propios presupuestos y en cierto modo consigo mismo, es decir, confrontándolo con sus propias consecuencias, y una crítica trascendente que tiene lugar desde fuera [...] Creo que la manera con que les he explicado esta diferencia, debería ser ya un potente argumento a favor de la convicción hegeliana de la prioridad de la crítica inmanente» (Th. W. Adorno, Philosophische Terminologie, vol. 2. Frankfurt a.M.: Suhrkamp, 1973, p. 236). 
(2012) «L. Löwenthal, La herencia de Calibán», en: Laguna, Revista de Filosofía, Servicio de Publicaciones de la Universidad de La Laguna. Traducción crítica.

Dirección electrónica: cescuelac@gmail.com 